\title{
Catalytic Dechlorination of Carbon Tetrachloride in Liquid Phase with Methanol as H-Donor Over Ag/C Catalyst
}

\author{
Mohong $\mathrm{Lu}^{1}$, Xuebing $\mathrm{Li}^{2}$, , Bo Chen ${ }^{1}$, Mingshi $\mathrm{Li}^{1}{ }^{1, *}$, Hongchuan $\mathrm{Xin}^{2}$, and Liang Song ${ }^{2}$ \\ ${ }^{1}$ School of Petrochemical Engineering, Changzhou University, Changzhou 213164, P. R. China \\ ${ }^{2}$ Key Laboratory of Biofuels, Qingdao Institute of Bioenergy and Bioprocess Technology, \\ Chinese Academy of Sciences, Qingdao 266101, P. R. China
}

\begin{abstract}
Catalytic hydrodechlorination of carbon tetrachloride $\left(\mathrm{CCl}_{4}\right)$ is an effective measure to remove $\mathrm{CCl}_{4}$ due to its pollutant character. The dechlorination of $\mathrm{CCl}_{4}$ to dichloromethane $\left(\mathrm{CH}_{2} \mathrm{Cl}_{2}\right)$ and chloroform $\left(\mathrm{CHCl}_{3}\right)$ with a molar ratio of 3:2 was catalyzed by carbon-supported silver $(\mathrm{Ag} / \mathrm{C})$ catalyst in methanol solution. It was proposed from the catalytic results and characterization (X-ray diffraction, transmission electron microscopy and $\mathrm{X}$-ray photoelectron spectroscopy) data that, the chloride ion is abstracted from adsorbed $\mathrm{CCl}_{4}$ by $\mathrm{Ag}$ to form $\mathrm{CCl}_{3}$ and $\mathrm{CCl}_{2}$ radicals and silver chloride $(\mathrm{AgCl})$, and meanwhile the dehydrogenation of methanol over $\mathrm{Ag}$ domains intrigues initial active $\mathrm{Ag}-\mathrm{H}$ species and formaldehyde $(\mathrm{HCHO})$; then the $\mathrm{CCl}_{3}$ and $\mathrm{CCl}_{2}$ radicals are combined with $\mathrm{Ag}-\mathrm{H}$ to generate reaction products $\left(\mathrm{CHCl}_{3}\right.$ and $\left.\mathrm{CH}_{2} \mathrm{Cl}_{2}\right)$ and $\mathrm{Ag}$, and the dehydrogenated product $\mathrm{HCHO}$ facilitates the regeneration of formed $\mathrm{AgCl}$ to $\mathrm{Ag}$ with formation of carbon monoxide and hydrogen chloride. The catalyst can be recovered and recycled, and there was no significant decrease in catalytic activity and selectivity after $4^{\text {th }}$ recycling.
\end{abstract}

Keywords: Dechlorination, Carbon Tetrachloride, Ag/C Catalyst, Methanol, Ag Nanoparticles, Reaction Mechanism.

\section{INTRODUCTION}

Carbon tetrachloride $\left(\mathrm{CCl}_{4}\right)$ has been catalogued as group IV material and banned due to its potential ozone layer depletion. Catalytic hydrodechlorination of $\mathrm{CCl}_{4}$ using supported or unsupported metal catalysts $(\mathrm{Pt}, \mathrm{Pd}$, $\mathrm{Ni}, \mathrm{Cu}, \mathrm{Fe}, \mathrm{Co}$, etc.) in gas phase has been intensively exploited to avoid the conventional expensive and polluting combustion process for its elimination. ${ }^{1}$ Conversion of $\mathrm{CCl}_{4}$ in liquid phase with bubble slurry reactor has been proved more advantageous than gaseous phase because of its high hydrophobility, high heat capacity and low vapour pressure, and its easy fouling on the catalytic active sites causing rapid deactivation. ${ }^{2,3}$

Here, we report the dechlorination of $\mathrm{CCl}_{4}$ in liquid phase with sole supported silver (Ag) catalyst to the dechlorinated products (dichloromethane and chloroform) by the combination of methanol decomposition.

\footnotetext{
*Authors to whom correspondence should be addressed.
}

\section{EXPERIMENTAL DETAILS}

\subsection{Catalyst Preparation}

The activated carbon (420-840 $\mu \mathrm{m}$, Sinopharm Chemical Reagent Co., Ltd.) was washed by refluxing in nitric acid $(1 \mathrm{~mol} / \mathrm{L})$ for $3 \mathrm{~h}$ prior to use, followed by drying in static air at $393 \mathrm{~K}$ overnight. The catalyst was prepared by incipient wetness impregnation of aqueous silver nitrate $\left(\mathrm{AgNO}_{3}\right)$ solution onto activated carbon support with the $\mathrm{Ag}$ content of $8 \mathrm{wt} . \%$, followed by drying at $393 \mathrm{~K}$ for $12 \mathrm{~h}$ and reduction at $673 \mathrm{~K}$ in flowing hydrogen $\left(\mathrm{H}_{2}\right.$, $25 \mathrm{ml} \mathrm{min}^{-1}$ ) for $3 \mathrm{~h}$. The catalyst was hereafter abbreviated as $\mathrm{Ag} / \mathrm{C}$ catalyst.

\subsection{Catalyst Characterization}

X-ray diffraction (XRD) patterns were obtained with a Rigaku D/MAX 2500 diffractometer with $\mathrm{Cu} \mathrm{K} \alpha$ radiation. The particle size was calculated from Scherrer equation: $\tau=(K \lambda) /(\beta \cos \theta)$, where $\tau$ is the mean size of the ordered (crystalline) domains, $K$ is the shape factor, 
$\lambda$ is the $\mathrm{X}$-ray wavelength, $\beta$ is the full width at half the maximum intensity (FWHM) in radians, and $\theta$ is the Bragg angle. Transmission electron microscopy (TEM) images were recorded on a JEM 2100 electron microscope (JEOL, Japan) with an acceleration voltage of $200 \mathrm{kV}$. The sample was ultrasonicated for $5 \mathrm{~min}$ in ethanol before the TEM measurement. Nitrogen sorption was determined at $77 \mathrm{~K}$ on a Micromeritics ASAP 2400 system in static measurement mode. The samples were outgassed at $673 \mathrm{~K}$ for $8 \mathrm{~h}$ prior to the sorption measurements. The total surface area $\left(S_{\mathrm{BET}}\right)$ and total pore volume $\left(V_{\text {total }}\right)$ were calculated by the Brunauer-Emmett-Teller (BET) model and the Barrett-Joyner-Halenda (BJH) method, respectively. X-ray photoelectron spectroscopy (XPS) spectra of the samples were recorded at room temperature using a Thermo-Multilab2000 system with $\mathrm{Mg}-\mathrm{K} \alpha$ radiation. The $\mathrm{C}(1 \mathrm{~s})$ line at $284.6 \mathrm{eV}$ was taken as a reference for binding energy (BE) calibration.

\subsection{Dechlorination of $\mathbf{C C l}_{4}$}

The dechlorination of $\mathrm{CCl}_{4}$ was conducted in a teflonlined autoclave $(100 \mathrm{ml})$ at $403 \mathrm{~K}$. Typically, $5 \mathrm{ml}$ of $\mathrm{CCl}_{4}$ (Sinopharm Chemical Reagent Co., Ltd., AR), $25 \mathrm{ml}$ of methanol $\left(\mathrm{CH}_{3} \mathrm{OH}\right.$, Sinopharm Chemical Reagent Co., Ltd., AR) and $0.3 \mathrm{~g}$ catalyst were first loaded into the autoclave, followed by purging with nitrogen $\left(\mathrm{N}_{2}\right.$, Tianhong Chemical Industrial Co., Ltd., $\geq 99.9 \%$ ) for 3 times. The reactor was then charged with 1.0 $\mathrm{MPa}$ nitrogen, followed by temperature increasing to $403 \mathrm{~K}$. Liquid samples were collected at interval of 1-2 $\mathrm{h}$ and analyzed by a Varian CP-3800 gas chromatograph equipped with a FID detector and a SE-30 capillary column $(30 \mathrm{~m} \times 0.53 \mathrm{~mm})$.

The conversion of $\mathrm{CCl}_{4}$ and selectivities to chloroform $\left(\mathrm{CHCl}_{3}\right)$ and dichloromethane $\left(\mathrm{CH}_{2} \mathrm{Cl}_{2}\right)$ were calculated as follows:

$$
\begin{gathered}
\mathrm{X}_{\mathrm{CCl}_{4}}(\%)=\left(1-\frac{\mathrm{C}_{\mathrm{mol}, \mathrm{CCl}_{4}}}{\mathrm{C}_{\mathrm{mol}, \mathrm{CCl}_{4}}+\mathrm{C}_{\mathrm{mol}, \mathrm{CHCl}_{3}}+\mathrm{C}_{\mathrm{mol}, \mathrm{CH}_{2} \mathrm{Cl}_{2}}}\right) \times 100 \\
\mathrm{~S}_{\mathrm{CHCl}_{3}}(\%)=\left(\frac{\mathrm{C}_{\mathrm{mol}, \mathrm{CHCl}_{3}}}{\mathrm{C}_{\mathrm{mol}, \mathrm{CHCl}_{3}}+\mathrm{C}_{\mathrm{mol}, \mathrm{CH}_{2} \mathrm{Cl}_{2}}}\right) \times 100 \\
\mathrm{~S}_{\mathrm{CH}_{2} \mathrm{Cl}_{2}}(\%)=\left(\frac{\mathrm{C}_{\mathrm{mol}_{,}, \mathrm{CH}_{2} \mathrm{Cl}_{2}}}{\mathrm{C}_{\mathrm{mol}, \mathrm{CHCl}_{3}}+\mathrm{C}_{\mathrm{mol}_{2}, \mathrm{CH}_{2} \mathrm{Cl}_{2}}}\right) \times 100
\end{gathered}
$$

where $\mathrm{C}_{\mathrm{mol}, \mathrm{CCl}_{4}}, \mathrm{C}_{\mathrm{mol}, \mathrm{CHCl}_{3}}$ and $\mathrm{C}_{\mathrm{mol}, \mathrm{CH}_{2} \mathrm{Cl}_{2}}$ are the molar fractions of $\mathrm{CCl}_{4}, \mathrm{CHCl}_{3}$ and $\mathrm{CH}_{2} \mathrm{Cl}_{2}$ in liquid phase, respectively; $\mathrm{X}_{\mathrm{CCl}_{4}}$ is the conversion of $\mathrm{CCl}_{4}$, and $\mathrm{S}_{\mathrm{CHCl}_{3}}$ and $\mathrm{S}_{\mathrm{CH}_{2} \mathrm{Cl}_{2}}$ are the selectivities to $\mathrm{CHCl}_{3}$ and $\mathrm{CH}_{2} \mathrm{Cl}_{2}$, respectively.

\subsection{Recycling Test}

The used catalyst was filtrated and then charged into an autoclave with additional 3 wt. \% fresh $\mathrm{Ag} / \mathrm{C}$ catalyst after each catalytic cycle (in order to compensate the loss of the used catalyst during the process of filtration and collection). $5 \mathrm{ml}$ of $\mathrm{CCl}_{4}$ and $25 \mathrm{ml}$ of $\mathrm{CH}_{3} \mathrm{OH}$ were then loaded into the autoclave, followed by purging with $\mathrm{N}_{2}$ for 3 times. The reactor was then charged with $1.0 \mathrm{MPa} \mathrm{N}_{2}$, followed by temperature increasing to $403 \mathrm{~K}$. Liquid samples were collected at interval of 1-2 $\mathrm{h}$ and analyzed by a Varian CP-3800 gas chromatograph equipped with a FID detector and a SE-30 capillary column $(30 \mathrm{~m} \times 0.53 \mathrm{~mm})$.

\section{RESULTS AND DISCUSSION}

\subsection{Characterization of Samples}

The Ag/C catalyst with Ag loading of 8 wt.\% was prepared by incipient wetness impregnation method. Briefly, $\mathrm{AgNO}_{3}$ solution was added onto acid-washed activated carbon support, followed by drying and reduction with flowing hydrogen. The surface area and the pore volume of prepared catalyst are $924 \mathrm{~m}^{2} \mathrm{~g}^{-1}$ and $0.45 \mathrm{ml} \mathrm{g}^{-1}$, respectively, indicating the intact of support textural structure after Ag loading by comparison with activated carbon support with BET surface area of $1025 \mathrm{~m}^{2} \mathrm{~g}^{-1}$ and pore volume of $0.49 \mathrm{ml} \mathrm{g}^{-1}$ (Table I). The XRD pattern of fresh catalyst (Fig. 1) indicates that $\mathrm{Ag}$ in the prepared catalyst is in metal form with particle size of $21 \mathrm{~nm}$, calculated from Scherrer equation.

\subsection{Dechlorination of $\mathbf{C C l}_{4}$}

The conversion of dechlorination of $\mathrm{CCl}_{4}$ with $\mathrm{Ag} / \mathrm{C}$ catalyst in methanol solution was measured in a teflon-line autoclave purged with $\mathrm{N}_{2}$ and compressed with $1.0 \mathrm{MPa}$ $\mathrm{N}_{2}$. Samples were taken at an interval of 1-2 h, and analyzed with gas chromatography. Figure 2 shows the conversion of $\mathrm{CCl}_{4}$ and selectivities to $\mathrm{CH}_{2} \mathrm{Cl}_{2}$ and $\mathrm{CHCl}_{3}$ over $\mathrm{Ag} / \mathrm{C}$ at $403 \mathrm{~K}$. The conversion of $\mathrm{CCl}_{4}$ increased with reaction time and selectivities to $\mathrm{CH}_{2} \mathrm{Cl}_{2}(60 \mathrm{~mol} \%)$ and $\mathrm{CHCl}_{3}(40 \mathrm{~mol} \%)$ were kept nearly constant at all reaction time, indicating the independent formation pathways of $\mathrm{CH}_{2} \mathrm{Cl}_{2}$ and $\mathrm{CHCl}_{3}$ from $\mathrm{CCl}_{4}$, and the marginal contribution of consecutive reactions. Moreover, the direct formation of adsorbed: $\mathrm{CCl}_{2}$ carbene during adsorption of $\mathrm{CCl}_{4}$ onto $\mathrm{Ag}$ domains has been proved previously, ${ }^{4}$ which can be converted to $\mathrm{CH}_{2} \mathrm{Cl}_{2}$ by combination of active hydrogen species followed by desorption. The robustness of self-prepared $\mathrm{Ag} / \mathrm{C}$ catalyst for the dechlorination of $\mathrm{CCl}_{4}$ was examined by recycling the used catalyst, no significant decrease in catalytic activity and selectivity changes were observed after 4th recycling (Fig. 3).

It is well known that $\mathrm{Ag}$ catalyst can catalyze selective oxidation of ethylene to ethylene oxide and methanol to formaldehyde. ${ }^{5}$ Moreover, dihydrogen can be activated by $\mathrm{Ag}$ catalyst to form $\mathrm{Ag}-\mathrm{H}$ species. ${ }^{6,7}$ Montoya et al.

Table I. Textural properties of activated carbon and $\mathrm{Ag} / \mathrm{C}$ catalyst.

\begin{tabular}{lcc}
\hline Sample & $S_{\mathrm{BET}}\left(\mathrm{m}^{2} \mathrm{~g}^{-1}\right)$ & $V_{\text {total }}\left(\mathrm{ml} \mathrm{g}^{-1}\right)$ \\
\hline Activated carbon & 1025 & 0.49 \\
Fresh Ag/C catalyst & 924 & 0.45 \\
\hline
\end{tabular}

J. Nanosci. Nanotechnol. 14, 7315-7318, 2014 


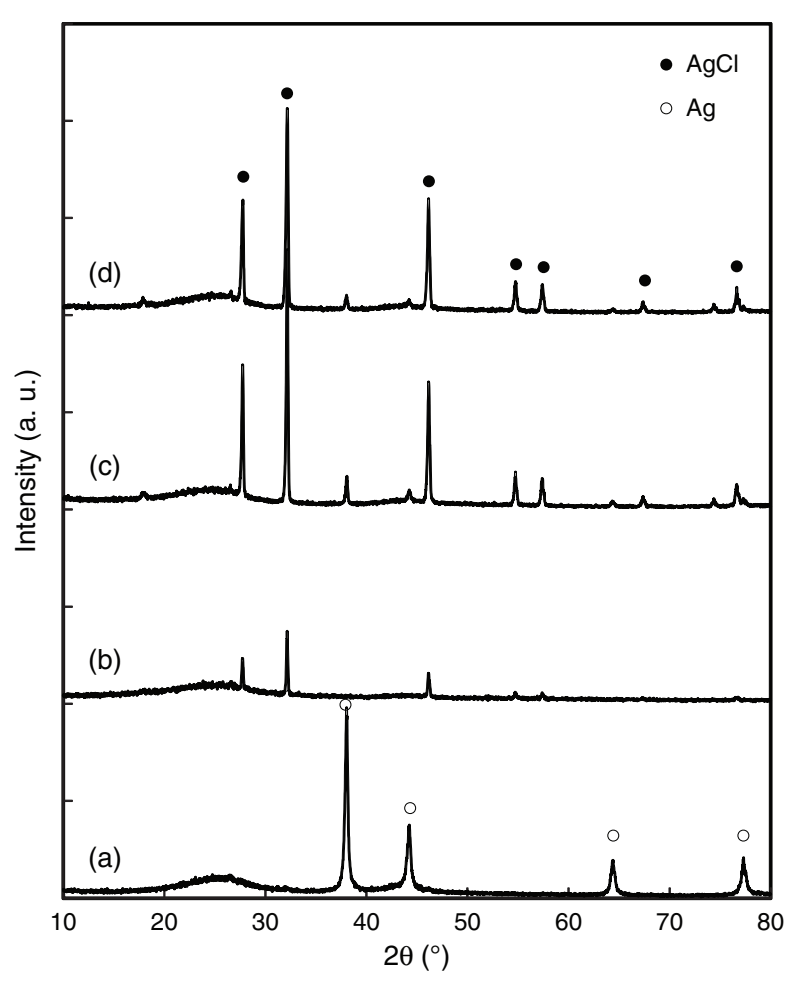

Figure 1. XRD patterns of (a) fresh $\mathrm{Ag} / \mathrm{C}$ catalyst, (b) used $\mathrm{Ag} / \mathrm{C}$ catalyst, (c) fresh $\mathrm{Ag} / \mathrm{C}$ catalyst after reaction with $5 \mu \mathrm{l}$ of $\mathrm{CCl}_{4}$ for $0.5 \mathrm{~h}$, and (d) fresh $\mathrm{Ag} / \mathrm{C}$ catalyst after reaction with $10 \mu \mathrm{l}$ of $\mathrm{CCl}_{4}$ for $0.5 \mathrm{~h}$.

reported that silver can catalyze dehydrogenation of alcohols in the absence of oxygen with formation of aldehydes. ${ }^{8}$ It was also reported that $\mathrm{Ag}$ is able to adsorb the chlorinated molecules such as chloromethane $\left(\mathrm{CH}_{3} \mathrm{Cl}\right),{ }^{9} \mathrm{CCl}_{4},{ }^{10}$ and 1,2-dichloroethane ${ }^{11}$ and break the $\mathrm{C}-\mathrm{Cl}$ bond. Here, we speculate that applied methanol in $\mathrm{CCl}_{4}$ dechlorination acts as not merely a solvent, but also a hydrogen providing reactant with the formation of active $\mathrm{Ag}-\mathrm{H}$ species via dehydrogenation catalyzed by Ag catalyst with the formation of formaldehyde. The direct formation of formaldehyde from

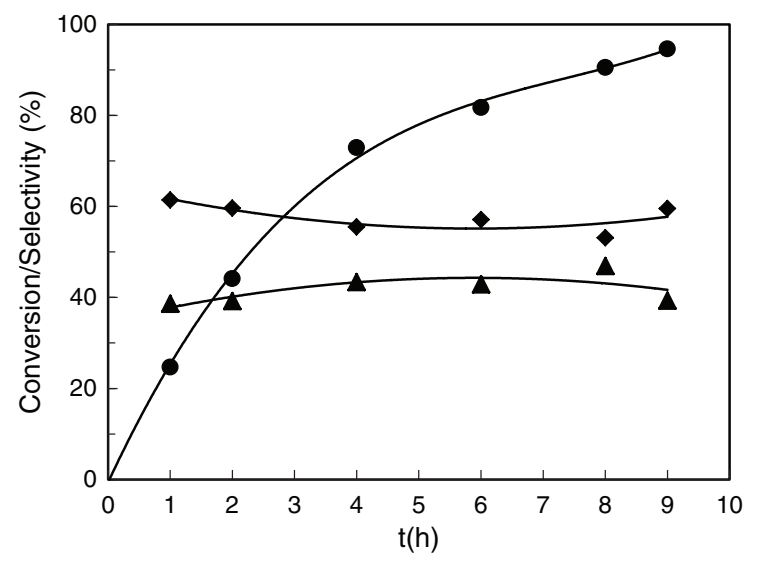

Figure 2. Conversion of $\mathrm{CCl}_{4}(\bullet)$ and selectivities of $\mathrm{CH}_{2} \mathrm{Cl}_{2}(\bullet)$ and $\mathrm{CHCl}_{3}(\boldsymbol{\Lambda})$ on $\mathrm{Ag} / \mathrm{C}$ catalyst (Reaction conditions: $0.3 \mathrm{~g}$ of catalyst, $5 \mathrm{ml}$ of $\mathrm{CCl}_{4}, 25 \mathrm{ml}$ of $\mathrm{CH}_{3} \mathrm{OH}, 1.0 \mathrm{MPa} \mathrm{N}_{2}, 403 \mathrm{~K}$ ).

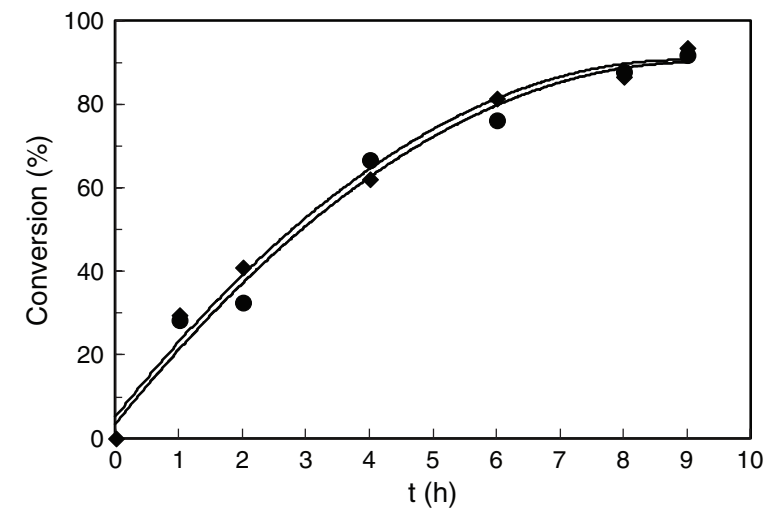

Figure 3. Conversion of $\mathrm{CCl}_{4}$ on $\mathrm{Ag} / \mathrm{C}$ catalyst for the first run $(\bullet)$ and the fourth run ( $)$ (Reaction conditions: $0.3 \mathrm{~g}$ of catalyst, $5 \mathrm{ml}$ of $\mathrm{CCl}_{4}$, $25 \mathrm{ml}$ of $\mathrm{CH} 3 \mathrm{OH}, 1.0 \mathrm{MPa} \mathrm{N}_{2}, 403 \mathrm{~K}$ ).

adsorbed methoxide on Ag has been observed during temperature programmed desorption (TPD) at relatively low temperatures, i.e., $290 \mathrm{~K} .{ }^{12,13}$ The hydrogen atoms will be converted to water or active hydrogen followed by desorption as $\mathrm{H}_{2}$ regarding the reaction conditions.

\subsection{Catalyst Changes After the \\ Dechlorination of $\mathbf{C C l}_{4}$}

The XRD pattern of used Ag/C catalyst (Fig. 1) indicates that $\mathrm{Ag}$ phase was partially converted to silver chloride $(\mathrm{AgCl})$ phase during catalyzing the dechlorination of $\mathrm{CCl}_{4}$. The particle size of $\mathrm{AgCl}$ phase in the used catalyst was $54 \mathrm{~nm}$, calculated from Scherrer equation, which is consistent with TEM images of fresh and used catalysts (Fig. 4). The particle size increasing would be related to the densities of $\mathrm{Ag}\left(10.5 \mathrm{~g} \mathrm{~cm}^{-3}\right)$ and $\mathrm{AgCl}\left(5.6 \mathrm{~g} \mathrm{~cm}^{-3}\right)$, as
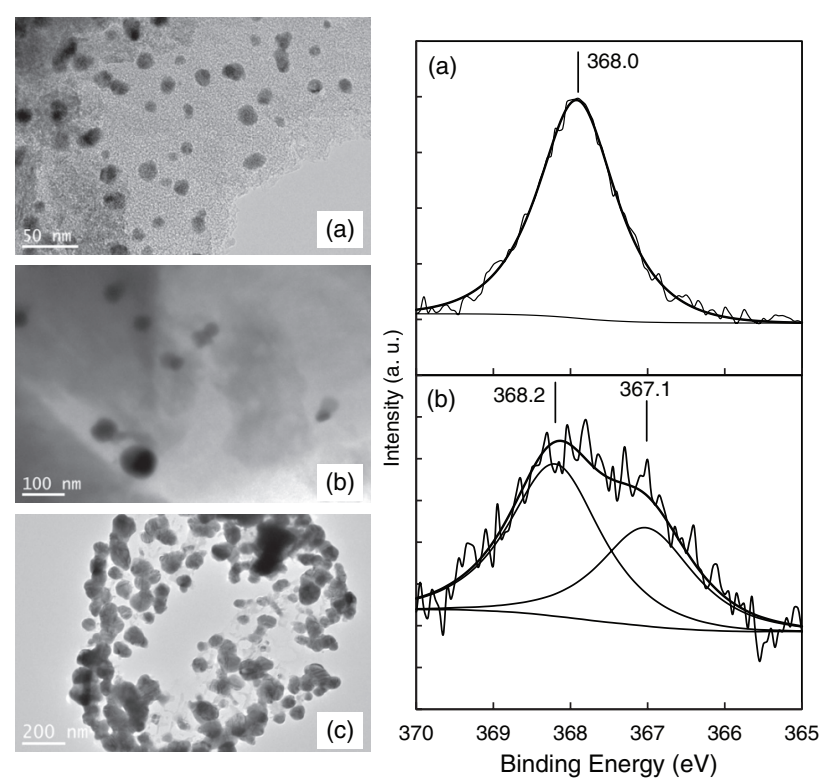

Figure 4. TEM images (left) and XPS (right) of (a) fresh Ag/C catalyst and (b), (c) used $\mathrm{Ag} / \mathrm{C}$ catalyst. 
Table II. Particle size of catalyst calculated from Scherrer equation.

\begin{tabular}{lc}
\hline Sample & $D(\mathrm{~nm})$ \\
\hline Fresh $\mathrm{Ag} / \mathrm{C}$ catalyst & 21 \\
Used $\mathrm{Ag} / \mathrm{C}$ catalyst & 54 \\
Fresh $\mathrm{Ag} / \mathrm{C}$ catalyst after reaction with $5 \mu \mathrm{l}$ of $\mathrm{CCl}_{4}$ for $0.5 \mathrm{~h}$ & 41 \\
Fresh $\mathrm{Ag} / \mathrm{C}$ catalyst after reaction with $10 \mu \mathrm{l}$ of $\mathrm{CCl}_{4}$ for $0.5 \mathrm{~h}$ & 47 \\
\hline
\end{tabular}

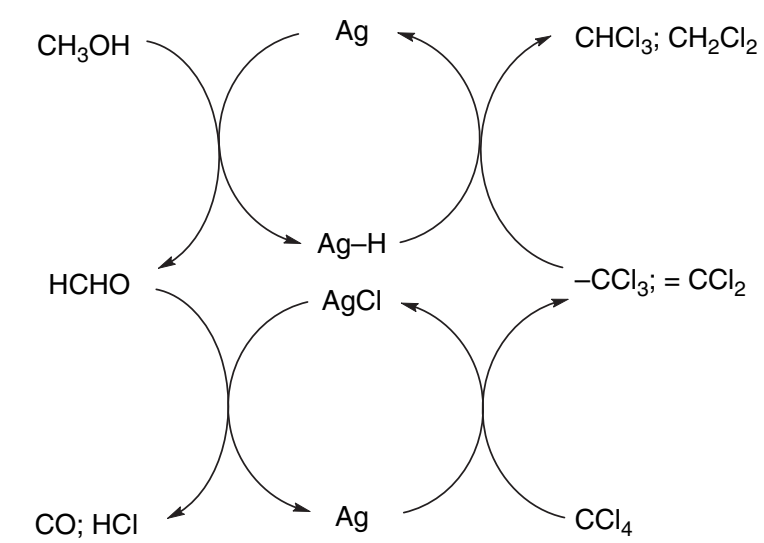

Figure 5. Reaction scheme for dechlorination of $\mathrm{CCl}_{4}$ by supported silver catalyst in the presence of methanol.

well as the incorporation of chloride ion $\left(\mathrm{Cl}^{-}\right)$into the $\mathrm{Ag}$ domains. The rapid transformation of $\mathrm{Ag}$ to $\mathrm{AgCl}$ during the reaction was also illustrated by adding trace amounts of $\mathrm{CCl}_{4}$ (5 and $10 \mu \mathrm{l}$, respectively) into the reactor and reacting for $0.5 \mathrm{~h}$, also shown in Figure 1 . The $\mathrm{AgCl}$ particle size increases with $\mathrm{CCl}_{4}$ amount monotonously (41 nm for $5 \mu \mathrm{l}$ of $\mathrm{CCl}_{4}$ added and $47 \mathrm{~nm}$ for $10 \mu \mathrm{l}$, Table II), indicating the incorporation of $\mathrm{Cl}^{-}$into the $\mathrm{Ag}$ particles. The certain degree of aggregation of $\mathrm{Ag}$ particles was found in the used catalyst (Fig. 4(c)), implying the weak interaction of $\mathrm{Ag}$ domains with activated carbon support. But no very large Ag particles were observed, indicating the sintering of $\mathrm{Ag}$ did not occur during the reaction, evidenced from the identical performance of recycled catalysts. The chemical states of surface silver species of used Ag/C catalyst were determined by XPS, ${ }^{14,15}$ calibrated with $\mathrm{C} 1 \mathrm{~s}$ $(284.6 \mathrm{eV})$. The XPS of used catalyst (Fig. 4) clearly shows that the coexistence of $\mathrm{Ag}$ and $\mathrm{Ag}^{1+}$ at the outer sphere of the reacted $\mathrm{Ag}$ particles, indicating the reduction of $\mathrm{AgCl}$ by formaldehyde ( $\mathrm{HCHO}$ ) with formation of carbon monoxide $(\mathrm{CO})$ and hydrogen chloride $(\mathrm{HCl})$, at elevated temperatures.

\subsection{Reaction Mechanism}

Here, we propose a plausible reaction mechanism for the dechlorination of $\mathrm{CCl}_{4}$ over sole $\mathrm{Ag}$ catalysts with methanol as hydrogen donor, involving the dehydrogenation of methanol to formaldehyde with the formation of $\mathrm{Ag}-\mathrm{H}$ active species and the abstraction of $\mathrm{Cl}^{-}$from adsorbed $\mathrm{CCl}_{4}$ by $\mathrm{Ag}$ to form $\mathrm{CCl}_{3}$ and $\mathrm{CCl}_{2}$ radicals, combined with $\mathrm{Ag}-\mathrm{H}$ to generate reaction products, $\mathrm{CHCl}_{3}$ and $\mathrm{CH}_{2} \mathrm{Cl}_{2}$. The regeneration of $\mathrm{Ag}$ from $\mathrm{AgCl}$ would be related to the $\mathrm{HCHO}$ intermediate (Fig. 5).

\section{CONCLUSION}

In summary, we reported here an efficient catalytic process for the dechlorination of $\mathrm{CCl}_{4}$ to $\mathrm{CH}_{2} \mathrm{Cl}_{2}$ and $\mathrm{CHCl}_{3}$ in liquid phase over sole silver catalysts, where methanol is taken as H-donor, and its dehydrogenated product, formaldehyde, facilitates the regeneration of formed $\mathrm{AgCl}$ to $\mathrm{Ag}$.

Acknowledgment: The authors greatly acknowledge the funding from NSFC (Grant Nos.: 20976076 and 21307009) and the Priority Academic Program Development of Jiangsu Higher Education Institutions (PAPD).

\section{References and Notes}

1. F. Alonso, I. P. Beletskaya, and M. Yus, Chem. Rev. 102, 4009 (2002).

2. V. I. Kovalchuk and J. L. d'Itri, J. Catal. 271, 13 (2004).

3. X. Wu, Y. A. Letuchy, and D. P. Eyman, J. Catal. 161, 164 (1996).

4. N. Bovet, D. I. Sayago, F. Allegretti, E. A. Kröger, M. J. Knight, J. Barrett, D. P. Woodruff, and R. G. Jones, Surf. Sci. 600, 241 (2006).

5. H. Zhang, Q. Fu, Y. X. Yao, Z. Zhang, T. Ma, D. L. Tan, and X. H. Bao, Langmuir 24, 10874 (2008).

6. J. Hohmeyer, E. V. Kondratenko, M. Bron, J. Kröhnert, F. C. Jentoft, R. Schlögl, and P. Claus, J. Catal. 269, 5 (2010).

7. K. Shimizu, Y. Miyamoto, and A. Satsuma, J. Catal. 270, 86 (2010).

8. A. Montoya and B. S. Haynes, J. Phys. Chem. C 111, 9867 (2007).

9. S. C. Fung and J. H. Sinfelt, J. Catal. 103, 220 (1987).

10. M. H. Lu, J. Z. Sun, D. B. Zhang, M. S. Li, J. J. Zhu, and Y. H. Shan, React. Kinet. Mech. Catal. 100, 99 (2010).

11. B. Heinrichs, J. P. Schoebrechts, and J. P. Pirard, J. Catal. 200, 309 (2001).

12. W. S. Sim, P. Gardner, and D. A. King, J. Phys. Chem. 99, 16002 (1995).

13. T. E. Felter, W. H. Weinberg, G. Y. Lastushkina, P. A. Zhdan, G. K. Boreskov, and J. Hrbek, Appl. Surf. Sci. 16, 351 (1983).

14. A. Samokhvalov, S. Nair, E. C. Duin, and B. J. Tatarchuk, Appl. Surf. Sci. 256, 3647 (2010).

15. H. Kannisto, H. H. Ingelsten, and M. Skoglundh, J. Mol. Catal. AChem. 302, 86 (2009).

Received: 30 November 2012. Accepted: 4 October 2013. 